\section{Ex ante Economic Evaluation of Technologies for Managing Postharvest Physiological Disorders: The Case of 'Empire' Apples in New York State}

\author{
Bradley J. Rickard ${ }^{3}$ \\ Charles H. Dyson School of Applied Economics and Management, Cornell \\ University, Ithaca, NY 14853
}

\author{
David R. Rudell ${ }^{1}$ \\ Tree Fruit Research Laboratory, USDA-ARS, Wenatchee, WA 98801
}

Christopher B. Watkins ${ }^{2}$

Horticulture Section, School of Integrative Plant Science, Cornell University, Ithaca, NY 14853

Additional index words. apples, biomarkers, economics of innovation, postharvest physiological disorders, technological change

\begin{abstract}
Recently there has been much progress in the development of technologies that use biomarkers to detect and manage postharvest physiological disorders for apples in long-term storage. Such technologies have the capacity to alleviate fruit loss by allowing storage operators to more effectively manage the disorder by adjusting stock distribution. The technology may also reduce costs for storage materials and associated management activities. However, as is common for many new technologies that have not yet been adopted commercially in agriculture, the net economic value of the technology is not well understood and is difficult to assess ex ante. In horticultural markets that include quality (and price) differentiated products, technologies that affect grading are expected to impact revenues in nontrivial ways. Here we develop a framework to assess the likely range of economic implications associated with the adoption of the biomarker technology that allows a greater share of fruit to be marketed in a higher grade and may influence the costs of storing fruit. Results indicate that $10 \%$ increases in the share of higher quality fruit lead to increased profits of between $0.99 \%$ and $3 \%$. A scenario that leads to a $10 \%$ increase in the share of fruit in higher grades and a $10 \%$ decrease in material costs for storage would increase profits by $\approx \mathbf{4} .4 \%$. Our analysis and results are specific to the case of biomarker use to manage postharvest disorders for 'Empire' [Malus sylvestris (L.) Mill var. domestica Borkh.] apples, yet the framework can be used with cultivar-specific price and yield information to assess the ex ante economic implications of adopting the technology more generally.
\end{abstract}

The economic implications of new technologies that may be commercialized are of paramount concern for industry stakeholders. Agricultural economists are keenly aware that producers face such choices and offer a range of practices to measure the potential benefits and costs of new technologies. Work has been

Received for publication 13 Nov. 2015. Accepted for publication 17 Mar. 2016.

This material is based on the work that is supported by the National Institute of Food and Agriculture, U.S. Department of Agriculture, under award number 2010-51181-21446 and by U.S. Department of Agriculture Cooperative Agreement number 58-3000-3-0021.

Any opinions, findings, conclusions, or recommendations expressed in this publication are those of the authors and do not necessarily reflect the view of the U.S. Department of Agriculture.

${ }^{1}$ Research Plant Physiologist.

${ }^{2}$ Professor.

${ }^{3}$ Corresponding author. E-mail: b.rickard@cornell. edu. done that focuses on specific technologies in specific industries; for example, Lemieux and Wohlgenant (1989) and Lesser et al. (1999) present frameworks to examine the ex ante economic impacts of specific biotechnologies in animal agriculture that had not yet been deregulated and commercialized. Much of this earlier work examined industries with relatively little product differentiation, and in the modeling effort the technology was assumed to affect all products in the same way. Horticultural crops, however, often are highly differentiated across, and even within, cultivars. For many fruit crops there are different grades, and then within each grade there are various size classifications. If new technologies introduced into horticultural markets affect products differentially, then the economic framework for evaluation needs to accommodate these idiosyncrasies.

An accurate ex ante evaluation of novel innovations is difficult when the benefits of the new technology to individual producers are not very well understood. This is further complicated in food and agricultural markets as new technologies are often controversial and the benefits are not shared equally to all constituents (including all products and all producers) in the supply chain. New technologies are typically described as either revenue enhancing or cost reducing. Revenue-enhancing technologies have the capacity to increase yields, increase quality, and influence prices if the final products are transformed or are able to enter new markets. Cost-reducing technologies often introduce innovations that reduce overall input use or allow producers to switch to less expensive inputs. In some cases, we observe innovations that are both revenueenhancing and cost-reducing.

The empirical example that motivates our work is the use of biomarkers to manage postharvest physiological disorders in longterm controlled atmosphere (CA) apple storage. Such disorders are nontrivial for some of the major apple cultivars produced in the United States, and they can lead to significant economic losses for apple producers (Rudell and Watkins, 2011). Some of the most critical physiological disorders that occur in apple storage include superficial scald for 'Granny Smith', soft scald for 'Honeycrisp', external $\mathrm{CO}_{2}$ injury for 'Empire', and firm-flesh browning for 'Empire' (see illustrations in Supplemental Fig. 1). Biomarker technologies have the capacity to be a revenue-enhancing technology if they provide reliable information that would allow the storage operator to reduce the share of downgraded fruit and/or to market a greater share of the stored fruit in higher quality grades. The biomarker technology could also lead to reduced costs if fewer materials are needed in storage.

Here, we focus specifically on firm flesh browning of the 'Empire' apple (Malus sylvestris var. domestica Borkh.), which is a major cause of revenue loss for growers and storage operators in New York State. 'Empire', is a cross between 'McIntosh' and 'Delicious' and was released in 1966 (Derkacz et al., 1993). It is a major cultivar in the northeastern United States, particularly in New York State as well as in Canada. 'Empire', at almost 1860 ha, was the second most planted cultivar after 'McIntosh' in the northeast in 2006 (USDA-NASS, 2012), and is the fifth most important cultivar in the United States with a total production of 170,000 tons in 2011 (Lehnert, 2012). Symptoms of flesh browning in 'Empire' typically become visible after several months in storage (in the May or June following harvest in the northern hemisphere), but can occur earlier in some years. Flesh browning is not externally visible and mostly starts at the stem end of the fruit in the shoulder region (Lee et al., 2012).

'Empire' apples are air stored to meet market demand until about December with fruit for marketing beyond this time usually being $\mathrm{CA}$ stored. Both air-stored and $\mathrm{CA}$ stored fruit are often treated with the inhibitor 
of ethylene perception, 1-methylcycopropene (Watkins, 2008). A storage period of at least 10 months is desired by the whole fruit and fresh cut industries, but the cultivar is susceptible to several physiological disorders that limit its storage potential (Watkins et al., 1997; Watkins and Liu, 2010). Flesh browning has been especially problematic for the fresh cut industry as only apples with no internal browning - even slight browning in the stem end region (shoulder) - are acceptable.

\section{Materials and Methods}

The objective of this research is to quantify the potential economic benefits of adopting biomarkers that would help to manage a specific postharvest physiological disorder for the Empire cultivar, namely flesh browning. Here, we outline a framework that uses information on prices and yields for specific grades and sizes of fruit, as well as data on the costs of production and storage. Essentially, we develop a tool to help the industry better understand the potential benefits of the biomarker technology and to provide a measure of the value of the new technology. We present results across a range of market simulations to provide a wider spectrum of the potential benefits of the biomarker technology.

Our analysis is done in three stages. In the first stage, we outline the annual costs of orchard production and the costs of storing 'Empire' fruit in a CA room. In the second stage, we employ a range of prices and yields to calculate revenues across the various grades and sizes of 'Empire' fruit. A range of net profits to the producer/storage operator can be evaluated using the information outlined in stages 1 and 2 . In the third stage, we simulate how the adoption of biomarkers might affect the shares of fruit marketed in the various grades, and ultimately how that would affect net profits.

The data used in our analysis were calculated based on those available in DeMarree (2010) and Gallardo and Galinato (2012) and then adjusted to reflect the market for 'Empire' fruit produced in New York State. The cost data in the earlier studies were adjusted to better reflect specific costs for disease and pest management practices for the cultivar, as well to add details about the costs of materials used in its storage. The revenue data were adjusted to consider the average yields and prices for the various grades and sizes of 'Empire' fruit produced in New York State. The cost and price data, and a more disaggregated version of the yield data were also used in Doerflinger et al. (2015), however, the data are being used here to answer a related but different research question. Doerflinger et al. (2015) focused on how harvest dates impact yields across the different fruit sizes, and compared the economic implications of marketing fruit that is harvested at different dates in the fall. This research is not concerned with the role of harvest dates on fruit size,

Table 1. Estimated costs for production, harvest, storage, and marketing for 12.15 ha of 'Empire'.

\begin{tabular}{|c|c|c|c|}
\hline Name & Costs per unit (\$) & $\begin{array}{l}\text { Units per } 2,000 \\
\text { bins or } 12.15 \text { ha }\end{array}$ & $\begin{array}{c}\text { Costs per } 2,000 \\
\text { bins or } 12.15 \text { ha }(\$)\end{array}$ \\
\hline \multicolumn{4}{|l|}{ Variable orchard costs } \\
\hline Harvest labor (ton) & 32.58 & 840 & $27,370.50$ \\
\hline Seasonal quality control (h) & 11.47 & 146 & $1,670.95$ \\
\hline FT truck/tractor driver $(\mathrm{h})$ & 17.54 & 146 & $2,555.22$ \\
\hline FT tractor driver $(\mathrm{h})$ & 14.37 & 146 & $2,093.42$ \\
\hline PT truck/tractor Driver $(\mathrm{h})$ & 12.71 & 146 & $1,851.59$ \\
\hline Interest on operating capital (ha) & 1,790 & 12.14 & $21,730.60$ \\
\hline $\begin{array}{l}\text { Disease control (Fungi, Insect/mite, } \\
\text { Herbicides) (ha) }\end{array}$ & 1,329 & 12.14 & $16,134.06$ \\
\hline Chemical thinners (ha) & 279 & 12.14 & $3,387.06$ \\
\hline Fruit thinning/return bloom (ha) & 1,483 & 12.14 & $18,003.62$ \\
\hline Fertilizer (ha) & 543 & 12.14 & $6,592.02$ \\
\hline \multicolumn{4}{|l|}{ Fixed costs } \\
\hline Total overhead expense (ha) & 919 & 12.14 & $11,156.66$ \\
\hline $\begin{array}{l}\text { Average equipment investment } \\
\text { replacement year (ha) }\end{array}$ & 692 & 12.14 & $8,400.88$ \\
\hline Operators' management only (ha) & 704 & 12.14 & $8,546.56$ \\
\hline Annual equipment expense (ha) & 514 & 12.14 & $6,239.96$ \\
\hline \multicolumn{4}{|l|}{ Storage costs } \\
\hline Marketing and packaging (ton) & 24.76 & 340 & $8,422.12$ \\
\hline Sorting and storing Bins (ton) & 13.18 & 340 & $4,484.76$ \\
\hline 1-MCP (SmartFresh) $\left(1.4 \mathrm{~m}^{3}\right)$ & 4,000 & 1 & $7,150.46$ \\
\hline Diphenylamine and application & & & $4,000.00$ \\
\hline Total costs for stored fruit & & & $159,790.50$ \\
\hline
\end{tabular}

FT = Full time; $\mathrm{PT}=$ Part time; $1-\mathrm{MCP}=1$-methylcycopropene.

Table 2. Unit prices per box (18.1 kg), yields, and revenue for 12.15 ha of 'Empire'.

\begin{tabular}{|c|c|c|c|c|c|c|}
\hline Grade/size & $\begin{array}{c}\text { Avg } \\
\text { fruit wt (g) }\end{array}$ & $\begin{array}{c}\text { Price per } \\
\text { box }(10 \text { yr avg })\end{array}$ & $\begin{array}{l}\text { Net price } \\
\text { per box } \\
\left(\text { less fees }^{2}\right)\end{array}$ & $\begin{array}{c}\text { Yield } \\
\text { (shares, \%) }\end{array}$ & $\begin{array}{c}\text { Yield } \\
\text { (boxes per } \\
12.15 \text { ha) }\end{array}$ & $\begin{array}{c}\text { Revenue } \\
\text { (\$ per } 12.15 \mathrm{ha})\end{array}$ \\
\hline \multicolumn{7}{|l|}{$\overline{\text { Extra Fancy }}$} \\
\hline 163 & 116 & 13.02 & 8.38 & 6.01 & 2,561 & 21,470 \\
\hline 150 & 128 & 9.15 & 5.90 & 9.12 & 3,888 & 22,924 \\
\hline 138 & 136 & 12.00 & 7.73 & 11.18 & 4,764 & 36,803 \\
\hline 125 & 153 & 12.72 & 8.19 & 13.34 & 5,687 & 46,573 \\
\hline 113 & 167 & 19.56 & 12.60 & 12.47 & 5,316 & 66,971 \\
\hline 100 & 190 & 18.53 & 11.93 & 8.18 & 3,485 & 41,586 \\
\hline 88 & 215 & 18.82 & 12.12 & 3.30 & 1,407 & 17,052 \\
\hline 80 & 238 & 19.57 & 12.61 & 1.05 & 446 & 5,625 \\
\hline 72 & 264 & 19.55 & 12.59 & 0.26 & 112 & 1,409 \\
\hline 64 & 298 & 18.17 & 11.70 & 0.05 & 21 & 249 \\
\hline $1.1 \mathrm{~kg}$ bags & 126 & 14.12 & 9.09 & 2.96 & 1,261 & 11,467 \\
\hline $1.25 \mathrm{~kg}$ bags & 114 & 12.48 & 8.04 & 2.99 & 1,275 & 10,245 \\
\hline \multicolumn{7}{|l|}{ Fancy } \\
\hline 138 & 136 & 8.55 & 5.51 & 2.38 & 1,016 & 5,593 \\
\hline 125 & 153 & 8.30 & 5.35 & 2.74 & 1,166 & 6,235 \\
\hline 113 & 167 & 6.43 & 4.14 & 2.14 & 913 & 3,778 \\
\hline 100 & 190 & 8.00 & 5.15 & 1.32 & 564 & 2,904 \\
\hline 88 & 215 & 6.57 & 4.23 & 0.45 & 192 & 811 \\
\hline 80 & 238 & 7.09 & 4.57 & 0.12 & 49 & 224 \\
\hline $1.1 \mathrm{~kg}$ bags & 126 & 10.60 & 6.83 & 3.52 & 1,502 & 10,255 \\
\hline \multicolumn{7}{|c|}{ Commercial/juice } \\
\hline 1,000 & & 4.00 & 2.58 & 16.43 & 7,003 & 18,039 \\
\hline Total & & & & 100 & 42,627 & 330,213 \\
\hline
\end{tabular}

${ }^{\mathrm{z}}$ Fees include a packing charge of $30 \%$ and a commission expense of $8 \%$. Costs for storage charges and materials used in storage are considered expenses and included in the costs shown in Table 1.

assumes all fruit is harvested at the conventional time, and uses data to reflect average yields for each grade and fruit size. Here, the focus is not on fruit size but on fruit grades. We are interested in simulating the economic implications of storage technologies that have the capacity to change the share of fruit that is marketed in higher grade categories.

The unit of observation for this exercise is $\approx 2000$ bins that each contains $382 \mathrm{~kg}$ of fruit, or $\approx 42,10018.1 \mathrm{~kg}$ boxes of fruit; this is the amount of fruit that is used to fill a typical storage room with 'Empire' fruit in New York State. If we assume that a highdensity orchard produces 567 18.1-kg boxes per hectare, then $\approx 42,000$ boxes of fruit from 12.15 ha is required to fill one storage room. Therefore, the costs and revenues discussed below are specific to 12.15 ha of fruit production and to one storage room of fruit. The values described below and used in our analysis are meant to be generally representative and to serve as references points; however, the framework is designed to easily accommodate other values that may more accurately reflect market conditions for a different storage operator or for a different cultivar.

In Table 1 we outline the categories of costs involved in the production and storage 


\begin{tabular}{|c|c|c|c|c|c|c|c|c|}
\hline \multirow[b]{2}{*}{ Scenario } & \multirow[b]{2}{*}{ Description } & Mean & Minimum & Maximum & $\begin{array}{l}\text { Standard } \\
\text { deviation }\end{array}$ & Median & $\begin{array}{c}\text { Frequency of } \\
\text { profits between } \\
\$ 165 \mathrm{k} \text { and } \$ 198 \mathrm{k}^{\mathrm{z}}\end{array}$ & $\begin{array}{l}\% \text { change in mean } \\
\text { profits compared } \\
\text { with baseline }\end{array}$ \\
\hline & & \multicolumn{5}{|c|}{ Dollars } & \multicolumn{2}{|c|}{ Percent } \\
\hline 1 & $\begin{array}{l}\text { Shift } 10 \% \text { fruit from } \\
\text { Fy to ExFy grade }\end{array}$ & 176,037 & 127,073 & 234,357 & 16,335 & 175,720 & 65.00 & 0.987 \\
\hline 2 & $\begin{array}{l}\text { Shift } 10 \% \text { fruit from } \\
\text { C to ExFy grade }\end{array}$ & 179,555 & 129,814 & 233,830 & 16,278 & 179,006 & 66.40 & 3.006 \\
\hline
\end{tabular}

${ }^{2}$ This range reflects the mean profits in scenario $4 \pm 1 \mathrm{SD}$.

Fy $=$ Fancy; ExFy $=$ Extra Fancy; $C=$ Commercial.

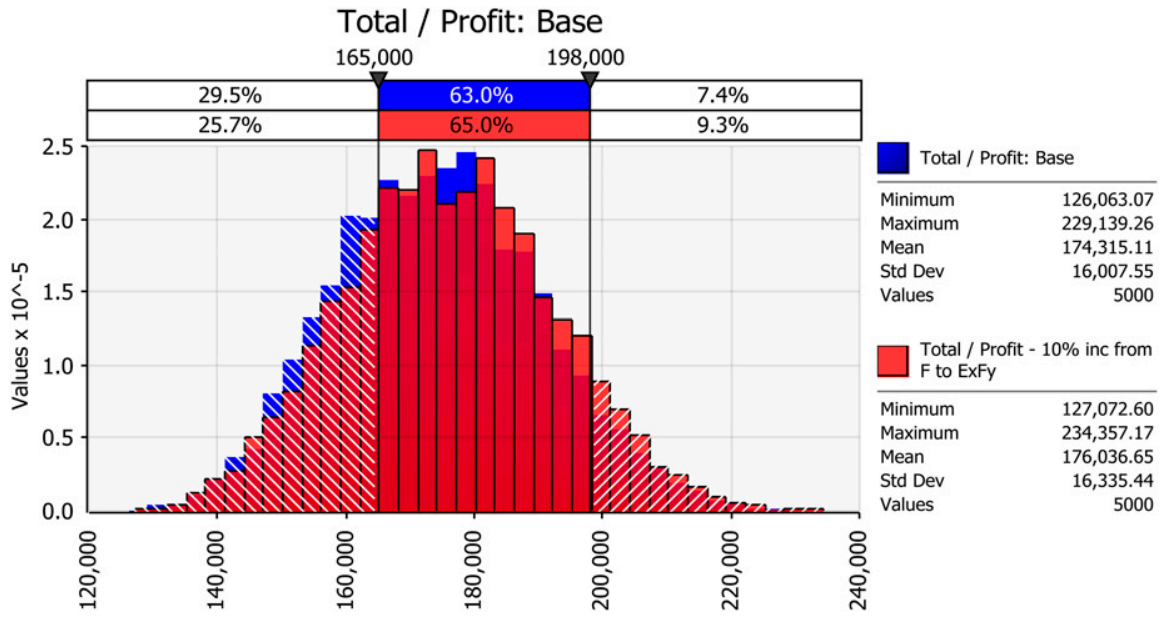

Fig. 1. Scenario 1: Profit distribution for shift of $10 \%$ fruit from Fancy to Extra Fancy.

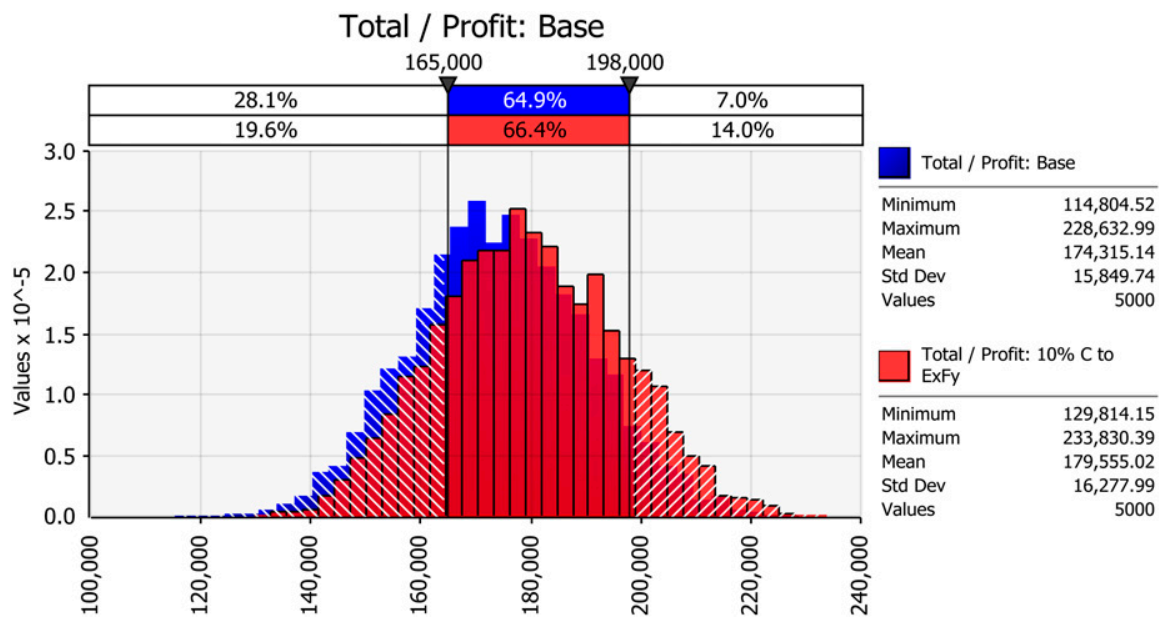

Fig. 2. Scenario 2: Profit distribution for shift of $10 \%$ fruit from Commercial to Extra Fancy.

of 42,000 boxes of fruit. Here, our objective is to characterize all of the costs involved in producing and storing the fruit; in some regions the fruit production and storage may be vertically integrated and controlled by a single firm, whereas in other regions these two activities may be operated by separate firms. Variable costs include labor requirements for harvesting and other orchard activities, interest on capital, and the materials applied to the orchard throughout the growing season. Fixed costs include expenses related to overhead, machinery and equipment, and operator salary. The storage costs reflect the costs for managing the fruit in long-term storage including sorting, packaging, and monitoring, and the materials used in storage. The storage costs do not include the fees collected by fruit marketing agency; these fees are deducted from the per box prices used to calculate revenue flows. Overall, variable costs represent $\approx 63 \%$ of total costs, fixed costs represent $\approx 22 \%$ of total costs, and storage costs represent $\approx 15 \%$ of the total costs.
Revenue is derived from prices and yields earned across the various sizes in the different grades of fruit. Four general quality grades are used in the United States: "U.S. Extra Fancy" (ExFy), "U.S. Fancy" (Fy), "U.S. no. 1" (no. 1), and "Commercial" (C) by the U.S. standards for grading of apples (USDA, 2002). In our analysis, we focus on the ExFy, Fy, and $\mathrm{C}$ grades given the very small share of 'Empire' fruit that is marketed in the no. 1 grade. ExFy is the highest grade and, therefore, brings the highest price; standards for fruit size and percent red cover for this grade are high, and in some years can be difficult to achieve for the bicolored cultivars. Whole fruit prices are determined by grade as well as size, which ranges between 72 and 163 fruit per box. This refers to an average fruit weight of $\approx 265$ to $116 \mathrm{~g}$. Fresh cut requires from 100 to 115 count boxes with individual fruit weight between 190 to $170 \mathrm{~g}$.

In Table 2 we show the 10 year average prices and yields by grade and then by size within each grade for 'Empire' apples produced and marketed in New York State. The average prices are calculated using data between 2002 and 2011 using industry data (Stannard, personal communication), and this is a period that included a relatively wide range of prices for apples. The prices are highest for the largest fruit in the ExFy grade, and lowest for the fruit in the $\mathrm{C}$ grade. The net price represents the price the storage operator (or the grower/storage operator if the fruit production and storage activities are vertically integrated) receives after deducting the appropriate marketing fees and commissions. The yield shares show the approximate percent of the total crop that falls into each grade/size category, and these shares are used to calculate the quantity of fruit marketed under the different grade/size categories.

\section{Results}

We simulate four scenarios that may unfold as a result of the adoption of the biomarker technology to manage physiological disorders in stored 'Empire' apples. The simulation work examines the economic effects of a biomarker technology that affects 1) revenue through changes in the share 


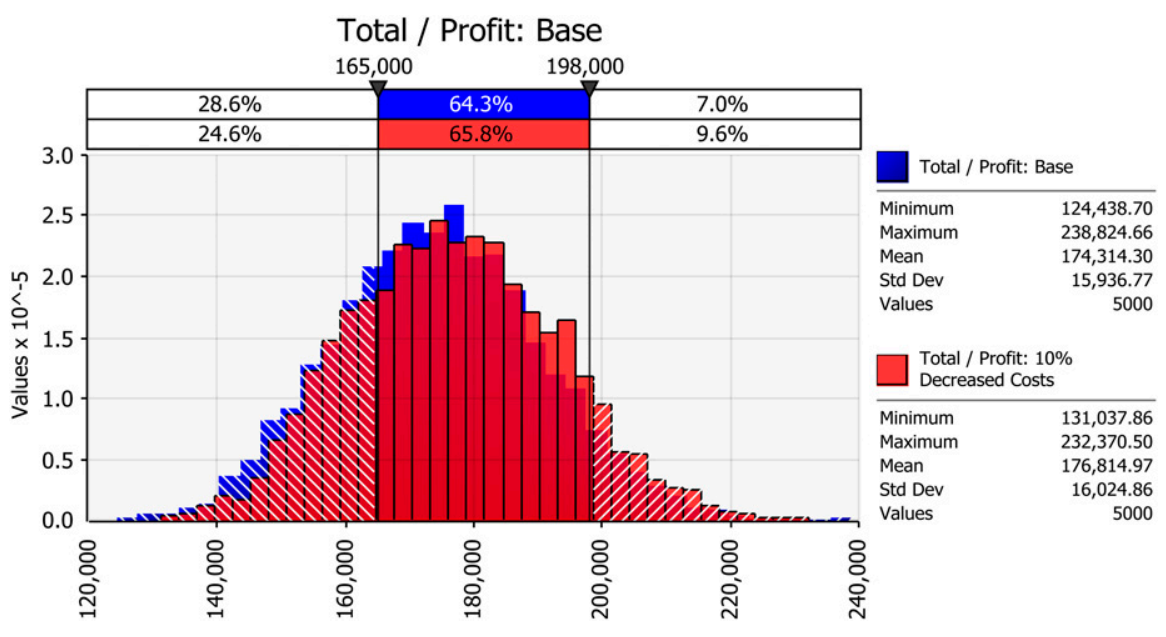

Fig. 3. Scenario 3: Profit distribution for reduction in storage costs by $10 \%$.

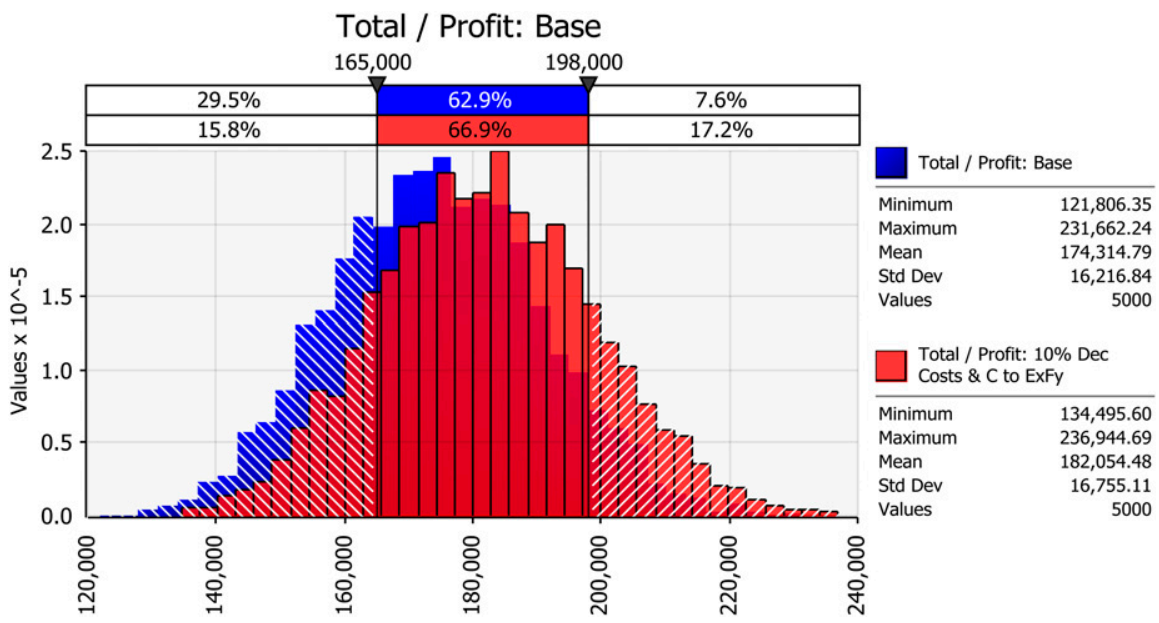

Fig. 4. Scenario 4: Profit distribution for shift of $10 \%$ fruit from Commercial to Extra Fancy plus a $10 \%$ reduction in storage costs.

of fruit that is marketed in the higher valued grades/sizes, 2) the cost of storing the fruit, and 3) some combination of changes in revenues and changes in costs. For each scenario, we manipulate the baseline cost and revenue data detailed in Tables 1 and 2 to assess the economic implications of a given change in the share of fruit marketed as higher quality or in the cost of storing the fruit. The actual changes in the share of fruit marketed to higher grades of fruit are not known with any certainty given that the biomarker technology has not been adopted commercially. The changes we assume are based on information collected from industry stakeholders that are reasonably familiar with the likely benefits of the technology. Furthermore, the changes that we consider are relatively modest. Results from each scenario are then compared with the baseline case to understand how the conditions in each scenario change net profits for the 12.15 $\mathrm{ha} / 2000$ bin unit of production.

The analysis was conducted with a simulation program that uses an iterative process to generate 10,000 probabilistic outcomes. We use the information about the range of prices over the 10 -year period to calculate an empirical distribution of prices for each
138 sizes by $10 \%$ and shift that to the corresponding sizes in the Extra Fancy grade. The full distribution of profits is shown in Fig. 1 and is summarized in Table 3. In this scenario, the mean profits increase by $\approx \$ 1700$ or by $0.99 \%$. In the second scenario, we shift $10 \%$ of fruit in the Commercial grade to the same four sizes of fruit in the Extra Fancy grade (in equal quantities). Figure 2 illustrates the distributional impacts on net profits for scenario 2, and Table 3 shows that the mean profits increase by $\approx \$ 5200$ or $3 \%$ compared with the baseline case.

In the third and fourth scenarios, we consider the outcome if the biomarker technology has the capacity to reduce storage costs via less use of diphenylamine (DPA) or less management of other resources used to store apples. In the third scenario, we model the effects of $10 \%$ lower storage costs and in the fourth scenario, we couple the lower storage costs with a reallocation of $10 \%$ of the Commercial grade fruit to the Extra Fancy grade. Figure 3 shows the distributional effects of a $10 \%$ reduction in storage costs, and Fig. 4 shows the distributional effects of the reduction in storage costs coupled with the shift in fruit marketed in the higher quality grade. As shown in Table 3, the reduction in costs alone does not have a significant effect of mean net profits (an increase of $1.4 \%$ ), but the effects are more significant when coupled with $10 \%$ of the fruit shifting from the Commercial grade to the Extra Fancy grade. In scenario 4, the mean net profits increase by $\approx \$ 8000$ compared with the baseline case, or by $4.4 \%$.

Policy considerations. The United States and the European Union (EU) have embarked on ambitious negotiations to create a comprehensive free trade agreement known as the Transatlantic Trade and Investment Partnership (TTIP). The agreement aims to promote trade between the two regions through three mechanisms: 1) increasing market access, 2) enhancing regulatory coherence and cooperation, and 3) developing and updating trade rules. Many expect that the TTIP negotiations concerning market access and trade rules will progress without significant debate (Akhtar and Jones, 2013), while the discussions concerning differences in domestic regulations will continue to be highly contested (Fontagné et al., 2013). There also exist a number of nontariff barriers that impact U.S.-EU trade in food and agricultural markets - many that are driven by regulatory differences between the regions - and in several cases quantifying the effects of these policies is not straightforward.

In apple markets, one of the key regulatory differences between the EU and the United States relates to the use of materials to manage pests and other issues in the orchard and in storage. The United States and the EU have regulations that govern the amount of material that can be found on domestically produced and imported food products known as maximum residue levels (MRLs), and there exist many examples 


\begin{tabular}{|c|c|c|c|c|c|c|c|c|}
\hline & & Mean & Minimum & Maximum & $\begin{array}{l}\text { Standard } \\
\text { deviation }\end{array}$ & Median & $\begin{array}{c}\text { Frequency of } \\
\text { profits between } \\
\$ 158 \mathrm{k} \text { and } \$ 190 \mathrm{k}^{\mathrm{z}}\end{array}$ & $\begin{array}{l}\% \text { change in mean } \\
\text { profits compared } \\
\text { with baseline }\end{array}$ \\
\hline Scenario & Description & & & Dollars & & & \multicolumn{2}{|c|}{ Percent } \\
\hline 5 & $\begin{array}{l}\text { Shift } 10 \% \text { fruit from Fy to } \\
\text { Commercial grade }\end{array}$ & 172,099 & 117,402 & 228,131 & 16,088 & 171,844 & 89.5 & -1.27 \\
\hline 6 & $\begin{array}{l}\text { Shift } 10 \% \text { fruit from ExFy to } \\
\text { Commercial grade }\end{array}$ & 150,355 & 107,382 & 202,614 & 14,179 & 150,242 & 29.5 & -13.75 \\
\hline 8 & $\begin{array}{l}\text { Shift } 10 \% \text { fruit from ExFy to } \\
\text { Commercial grade and } \\
\text { increase storage costs by } 10 \%\end{array}$ & 147,855 & 103,823 & 195,043 & 14,347 & 147,611 & 24.5 & -15.18 \\
\hline
\end{tabular}

${ }^{2}$ This range reflects the mean profits in scenario $0 \pm 1 \mathrm{SD}$.

$\mathrm{Fy}=$ Fancy; ExFy $=$ Extra Fancy; $\mathrm{C}=$ Commercial.

where there are nontrivial differences in MRLs between EU member states and the United States. These differences are often considered to be nontariff barriers which reduce trade and can complicate trade negotiations such as those concerning the TTIP. In particular, the EU has recently banned the use of DPA as a material in apple storage, and this is a product that has been widely used by storage operators in the United States to control postharvest physiological disorders for selected apple cultivars. Therefore, if the biomarker technology could be effectively used to alleviate the need for DPA (or other storage materials), it may be able to help secure export markets that have banned DPA and may also reduce the net costs of storage. Conversely, a ban on DPA in the absence of other solutions to manage postharvest physiological disorders could have large negative implications for apple producers and storage operators. It is critical to consider how this ban on the use of DPA will affect U.S.-EU trade in apples, and how it will impact profitability of producing and storing apples for EU export markets.

The framework developed here can give us a better understanding for how the adoption of biomarker technologies could mitigate the economic consequences of this ban on DPA to U.S. apple producers and storage operators. We conduct four additional scenarios that examine the economic implications of a ban on DPA in the absence of an effective replacement technology (such as biomarkers). Here, we consider the effects if $10 \%$ of the Fancy or Extra Fancy fruit is diverted to Commercial grade, and also consider scenarios with a $10 \%$ shift in fruit from Extra Fancy to Commercial grade plus changes in the net costs of storage. The results for these scenarios are shown in Table 4, and each scenario is compared with the baseline case.

We find that shifting fruit from the Fancy grade to the Commercial grade does not have a significant economic impact (net profits to the growers and storage operators fall by $1.3 \%$ ), however, if the ban on DPA results in a shift of $10 \%$ of Extra Fancy fruit to Commercial grade fruit, the economic effects are much larger (a decrease in net profits of $13.8 \%$ ). The final two scenarios show the economic implications for a shift in the share of fruit marketed as Commercial grade coupled with changes in storage costs. We consider both a net decrease in storage costs (if the reduction in costs for DPA is not outweighed by other additional storage costs) and a net increase in storage costs (if the reduction in costs for DPA is outweighed by other additional storage costs for materials and management labor). The final row shows that a shift of $10 \%$ in fruit from the Extra Fancy grade to the Commercial grade plus a net increase in storage costs would reduce net profits by $15.2 \%$. These results suggest that the ban on DPA could be significant, and crucially important for producers and storage operators following guidelines to export fruit to European markets.

\section{Conclusion}

The apple market includes a wide range of quality differentiated products (across cultivars, grades, and sizes). The introduction of new technologies in this market can significantly influence how the product is categorized. Therefore, new technologies introduced into markets with highly differentiated products need to be examined carefully. In addition, when prices across the differentiated products vary, and when technologies allow for improvements in quality, the economic effects could be substantial. We study the effects of introducing biomarker technologies that manage postharvest physiological disorders for the 'Empire' apple cultivar.

However, our framework is more generalizable and could be used to examine similar issues for other apple cultivars, other crops, and other technologies. For example, if we collected price and yield information across the various grades and sizes for other apple cultivars that were also subject to postharvest physiological disorders (like those shown in Supplemental Fig. 1), we could extend our analysis to assess the ex ante economic implications of adopting biomarker technologies more generally. The net benefits of adopting the technology would increase for cultivars that have larger price premiums for higher quality (i.e., higher grades of) fruit. Therefore, our results shown here are expected to serve as a lower bound for other cultivars that have larger price premiums for higher quality fruit.

Our results show that even small changes in the share of fruit that can be marketed in higher grades has the capacity to significantly impact the net profits to the producer and storage operator. For a $12.15 \mathrm{ha} / 2000$ bin storage unit, a $10 \%$ increase in the share of Commercial grade fruit marketed as Extra Fancy fruit would increase the net profits by $\approx 3 \%$. Increasing this share of fruit plus a decrease in storage-related costs by $10 \%$ would increase net profits by $4.4 \%$.

Here, we use detailed cost, price, and yield data for 'Empire' apples to assess the net benefits to apple producers and storage operators per 2000 bin room (or equivalently to 12.15 ha of orchard). The net benefits that we calculate provide a starting point for assessing the value of the technology to potential adopters. In some ways, this exercise provides us with a framework for evaluating a technology ex ante, or before the technology is fully commercialized and adopted. Effectively, the results from the scenarios allow stakeholders to better understand the industry's maximum willingness to pay for a new technology in cases where the cost and the price of the technology are not well documented, and where it is not yet widely available.

\section{Literature Cited}

Akhtar, S.I. and V.C. Jones. 2013. Proposed Transatlantic Trade and Investment Partnership (TTIP): In brief. Congressional Research Service Report for Congress Report No. R43158 11 Feb. 2016. <https://www.fas.org/sgp/crs/ row/R43158.pdf>.

DeMarree, A., T.L. Robinson, S. Hoying, and D. Breth. 2010. Fresh Apple NPV Analysis - Excel workbook. 10 Feb. 2016. <http://lof.cce. cornell.edu/submission. .php id $=268 \&$ crumb $=$ business \% 7Cbusiness $>$.

Derkacz, M., D.C. Elfving, and C.G. Forshey. 1993. The history of the 'Empire' apple. Fruit Var. J. 47:70-71.

Doerflinger, F.C., B.J. Rickard, J.F. Nock, and C.B. Watkins. 2015. An economic analysis of 
harvest timing to manage the physiological storage disorder firm flesh browning in 'Empire' apples. Postharvest Biol. Technol. 107:1-8.

Fontagné, L., J. Gourdon, and S. Jean. 2013. Transatlantic Trade: Whither Partnership, Which Economic Consequences?" Centre d'Etudes Prospectives et d'Informations Internationales (CEPII), CEPII Policy Brief No. 2013-1. 11 Feb. 2016. <http://www.cepii.fr/ PDF_PUB/pb/2013/pb2013-01.pdf $>$.

Gallardo, K. and S.P. Galinato. 2012. Cost estimates of establishing, producing, and packing Red Delicious apples in Washington. 10 Feb. 2016. <http://cru.cahe.wsu.edu/ CEPublications/FS099E/FS099E.pdf $>$.

Lee, J., L. Cheng, D.R. Rudell, and C.B. Watkins. 2012. Antioxidant metabolism of 1-methylcyclopropene
(1-MCP) treated 'Empire' apples during controlled atmosphere storage. Postharvest Biol. Technol. 65:79-91.

Lehnert, R. 2012. The Empire State apple. GoodFruit Grower 63:46.

Lemieux, C. and M.K. Wohlgenant. 1989. Ex ante evaluation of the economic impact of agricultural biotechnology: The case of porcine somatotropin. Amer. J. Agr. Econ. 71(4):903-914.

Lesser, W., J. Bernard, and K. Billah. 1999. Methodologies for ex ante projections of adoption rates for agbiotech products: Lessons learned from rBST. Agribusinss 15 (2): 149-162.

Rudell, D.R. and C.B. Watkins. 2011. Predicting storage disorders by developing diagnostic toolboxes. New York Fruit Qrtly 19(4):21-24.
USDA, 2002. United States Standard for Grades of Apples. <http://www.ers.usda.gov/data-products/ chart-gallery/detail.aspx? chartId=30486\#.VEl4V_ nF9FM>.

USDA-NASS. 2012. New York Apple Tree Survey. U.S. Dept. Agr., Natl. Agr. Stat. Serv., Washington, D.C.

Watkins, C.B. 2008. Overview of 1-methylcyclopropene trials and uses for edible horticultural crops. HortScience 43:86-94.

Watkins, C.B. and F.W. Liu. 2010. Temperature and carbon dioxide interactions on quality of controlled atmosphere-stored 'Empire' apples. HortScience 45:1708-1712.

Watkins, C.B., K.J. Silsby, and M.C. Goffinet. 1997. Controlled atmosphere and antioxidant effects on external $\mathrm{CO}_{2}$ injury of 'Empire' apples. HortScience 32:1242-1246. 

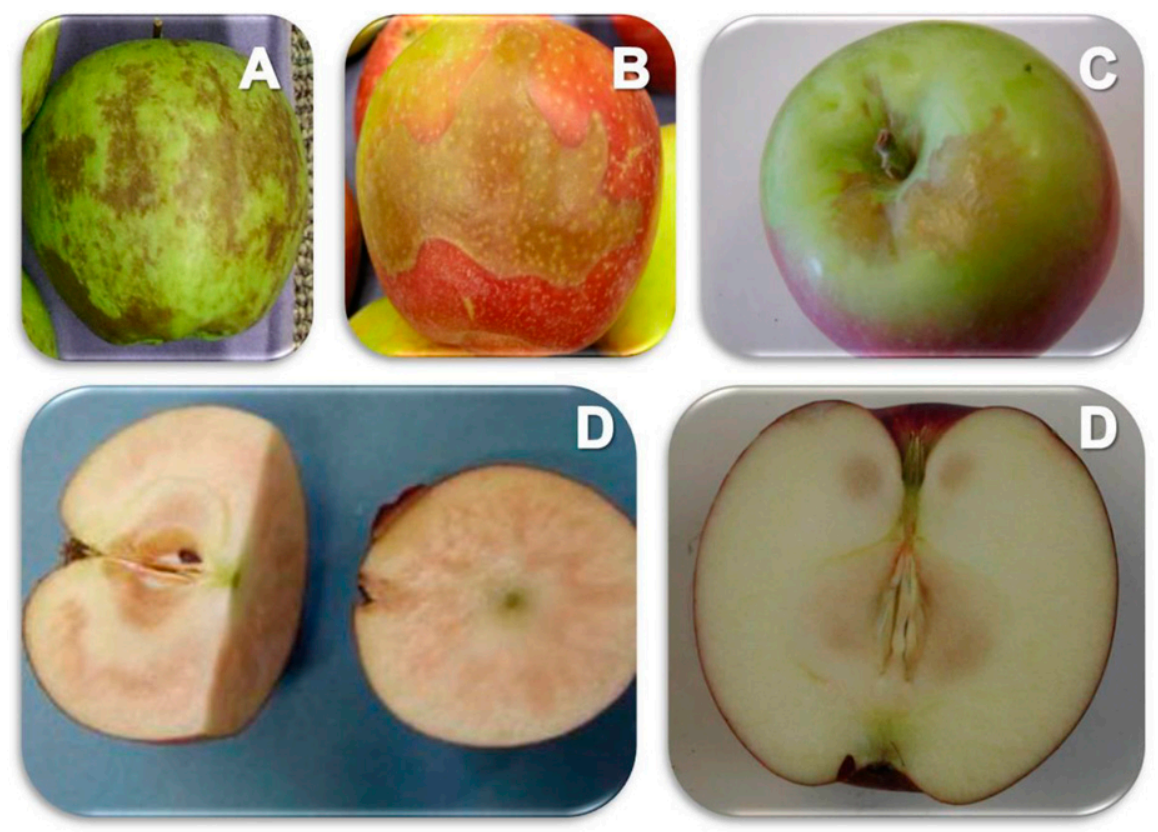

Supplemental Fig. 1. Illustrations of disorders for selected cultivars. Note: (A) superficial scald/'Granny Smith', (B) soft scald (internal-soggy breakdown)/'Honeycrisp', (C) external $\mathrm{CO}_{2}$ injury/'Empire', (D) firm-flesh browning/'Empire'. 